\title{
DETERMINANTS OF THE FLOW AND COMPOSITION OF BILE IN THE UNANESTHETIZED DOG DURING CONSTANT INFUSIONS OF SODIUM TAUROCHOLATE *
}

\author{
BY HENRY O. WHEELER † AND OSWALDO L. RAMOS $\ddagger$ \\ (From the Department of Medicine, Columbia University College of Physicians and Surgeons \\ and the Presbyterian Hospital, New York, N. Y.)
}

(Submitted for publication August 3, 1959; accepted August 27, 1959)

Physiological factors affecting the flow and composition of bile may be divided into two general categories. First, the availability of bile salts (by hepatic synthesis and by reabsorption from the bowel) has a significant influence on the rate of bile production. The choleretic effect of natural bile salts and the phenomenon of enterohepatic circulation of these compounds were first demonstrated by Schiff in 1870 (1). These observations have been confirmed by many workers since that time. It has been estimated that 85 to 90 per cent of the bile salt excreted in the bile is reabsorbed and returned to the liver $(2,3)$. For this reason the entry of bile itself into the duodenum provides a major stimulus for further bile production. Second, factors independent of the availability of bile salts can affect bile production. This category would include, for example, neural stimuli $(4,5)$, humoral agents such as secretin $(6-8)$ and changes in vascular perfusion (5).

During any investigation of biliary secretion in which bile is removed and not replaced, achievement of a steady state is thwarted by progressive depletion of bile salts which would normally undergo enterohepatic circulation. In the present studies this problem has been circumvented by constant intravenous infusion of sodium taurocholate. The results substantiate the important role of active bile salt secretion in the process of bile production and also suggest that the flow and composition of bile are modified by the addition of variable amounts of a solution which is similar in certain respects to pancreatic juice.

\section{METHODS}

All studies were conducted on four trained adult female mongrel dogs ( 21 to $30 \mathrm{Kg}$.) which had been pre-

* This investigation was supported by a grant from the Department of the Army (Contract DA-49-007-MD-205).

$\dagger$ Markle Scholar in Medical Science.

$\ddagger$ Rockefeller Traveling Fellow in Medicine. pared several months previously by splenectomy, cholecystectomy and installation of a Thomas duodenal fistula apparatus (9). Food and water were withheld for 15 hours prior to each study. The fistula was opened and a No. 5 or No. 6 Fr. olive-tipped ureteral catheter inserted into the ampulla of Vater and advanced about $5 \mathrm{~cm}$. into the common bile duct. The animal was then placed upright in a sling. Bile was withdrawn by gentle aspiration using an oiled tuberculin syringe, and collected under mineral oil in graduated tubes. By noting the volume collected, frequent estimations of bile flow were obtained (at intervals of 2 to 10 minutes depending on the flow). Approximately $4 \mathrm{ml}$. of bile was required to carry out all of the analytical procedures, and specimens were selected for analysis which represented periods of relatively constant flow in order to minimize "dead space" errors (due to the volume of bile in the hepatic ducts and the catheter). Specimens were rejected when obvious changes in flow occurred during their collection or during the collection of the preceding $2 \mathrm{ml}$. of bile. The figure of $2 \mathrm{ml}$. represents a rough estimate of "dead space" based on our observation of the approximate volume of bile one must collect before noting the presence of high concentrations of intravenously injected sulfobromophthalein sodium.

The "sodium taurocholate" used for intravenous infusion was a commercial preparation ${ }^{1}$ in which it was found that bile salt accounts for approximately 75 per cent of the total solids. Approximately 25 per cent of the bile salt is derived from dihydroxy rather than trihydroxy cholanic acid, but virtually all of it appears to be conjugated with taurine since only a trace of glycine was detected after hydrolysis. This material was dissolved in normal saline and passed through a Seitz filter. In a majority of studies a 1 per cent solution was infused through a nylon intravenous catheter at approximately $1 \mathrm{ml}$. per minute using a Bowman pump. In a few of the later studies a 2 per cent solution was infused at $1.5 \mathrm{ml}$. per minute. The rates of bile salt infusion stated in the text were calculated by multiplying the calibrated rate of delivery of the Bowman pump by the measured concentration of bile salt in the infusion mixtures. Hemolysis was minimal or, in most instances, undetectable after infusions lasting up to five hours.

Secretin ${ }^{2}$ was diluted to 10 units per $\mathrm{ml}$. in normal

1 Purchased from Nutritional Biochemicals Corp.

2 Supplied by Eli Lilly \& Co. through the courtesy of Dr. James B. Hammond. 
saline and administered intravenously in doses of 100 units. Acetazolamide ${ }^{3}$ was diluted to $100 \mathrm{mg}$. per ml. in normal saline and administered intravenously in doses of $65 \mathrm{mg}$. per $\mathrm{Kg}$. Intraduodenal infusions of $0.05 \mathrm{~N}$ hydrochloric acid in normal saline were administered at $7 \mathrm{ml}$. per minute by way of a catheter inserted through the duodenal fistula and advanced about $5 \mathrm{~cm}$. distal to the fistula.

The $\mathrm{pH}$ was measured anaerobically in each bile specimen immediately after collection by means of a Cambridge $\mathrm{pH}$ apparatus. Total $\mathrm{CO}_{2}$ content was determined by the method of Van Slyke and Neill (10) and bicarbonate concentration calculated by the Henderson-Hasselbalch equation assuming $\mathrm{a} \mathrm{pK}_{\mathrm{a}}$ of 6.1 . Sodium and potassium were measured by flame photometry, chloride by the method of Cotlove, Trantham and Bowman (11), and freezing point depression in a Fiske osmometer. Bile acid concentrations were determined by the method of Mosbach, Kalinsky, Halpern and Kendall (12).4 This method has yielded a recovery of $96.5 \pm$ S.D. 3.3 per cent in our laboratory. Although appreciable amounts of dihydroxy bile acids were found in the bile, the total concentration of conjugated bile acid will be referred to as "taurocholate" hereafter for convenience. Estimations of amylase were carried out on bile and on serial dilutions of duodenal juice in water and in bile by mixing $0.2 \mathrm{ml}$. of the test material with $0.4 \mathrm{ml}$. of a 0.5 per cent starch solution in $\mathrm{pH} 7.0$ phosphate buffer and incubating in a $37^{\circ} \mathrm{C}$. water bath for two minutes. A positive test consisted of absence of blue color on addition of iodine. When applied either to pure pancreatic juice or to pancreatic juice diluted in bile, this method has proven to be equally sensitive for the detection of pancreatic amylase.

\section{RESULTS}

\section{A. Relationship of taurocholate to other electrolytes}

Bile acid concentrations were measured on a total of 27 bile specimens of widely varying composition selected at random during the course of these studies. It was found that, within the limits of methodological error, the measured taurocholate concentration $\left[\mathrm{T}^{-}\right]$was equal to the difference between the cations $\left(\mathrm{Na}^{+}+\mathrm{K}^{+}\right)$and the anions $\left(\mathrm{Cl}^{-}+\mathrm{HCO}_{3}^{-}\right)$. The ratio: $\left[\mathrm{T}^{-}\right] /\left[\left(\mathrm{Na}^{+}+\mathrm{K}^{+}\right)-\right.$ $\left.\left(\mathrm{Cl}^{-}+\mathrm{HCO}_{3}^{-}\right)\right]$was equal to $0.98 \pm$ S.D. 0.09 over a range of taurocholate concentrations from 40 to $280 \mathrm{mEq}$. per L. Thus it appeared that the taurocholate concentration in hepatic bile could be estimated by the formula $\left[\mathrm{T}^{-}\right]=\left[\left(\mathrm{Na}^{+}+\mathrm{K}^{+}\right)\right.$

\footnotetext{
${ }^{3}$ Supplied as the sodium salt of Diamox $\$$ by Lederle Laboratories through the courtesy of Dr. George $\mathrm{K}$. Morlan.

4 Cholic acid and deoxycholic acid suitable for analytical standards were supplied by Ames Co., Inc. through the generosity of Dr. Norman L. Heminway.
}

$\left.-\left(\mathrm{Cl}^{-}+\mathrm{HCO}_{3}^{-}\right)\right]$with a degree of accuracy approximately equal to that obtainable by direct measurement of the bile acids. The taurocholate concentrations stated hereafter have all been calculated by this equation.

\section{B. Osmolality}

The osmolality of 67 bile samples, as estimated by freezing point depression, showed little variation ( $299 \pm$ S.D. $11 \mathrm{mOsm}$. per Kg.) despite marked differences in electrolyte composition, bile flow and time of collection. Thus in the present experimental situation the bile appeared always to be virtually isosmotic with respect to plasma (mean plasma osmolality $303 \pm$ S.D. 4 mOsm. per $\mathrm{Kg}$.). This observation is consistent with the demonstration by Gilman and Cowgill (13) that bile is in osmotic equilibrium with plasma even when the osmolality of the latter is made to vary over a wide range in the dog. Other workers have also found bile to be essentially isosmotic in dogs and in many other species (14).

\section{Composition of "common duct bile"}

At the time of catheterization approximately 6 to $10 \mathrm{ml}$. of bile could always be withdrawn from the common bile duct. This bile, referred to hereafter as "common duct bile," must have been secreted over a period of one to several hours prior to the study and retained in the duct system by the normal action of the sphincter of Oddi. The composition of "common duct bile," based on analysis of 16 specimens, was different from that of most subsequent samples of flowing hepatic bile but quite similar to the composition of canine gall bladder bile reported by others (15) and confirmed in two instances in this laboratory. As shown in the example in Figure 1, the concentration of taurocholate in "common duct bile" was typically very high. Taurocholate concentrations in three of the four dogs ranged between 200 and 280 $\mathrm{mEq}$. per L. (average $247 \mathrm{mEq}$. per L. in 13 specimens), and the concentrations of chloride and bicarbonate were low (range 8.4 to 26.6 and 1.5 to $7.2 \mathrm{mEq}$. per L., respectively) as was the $\mathrm{pH}$ (5.95 to 6.83). However, in one dog, in a total of three specimens, the "common duct" taurocholate concentration never exceeded 134 mEq. per L., and higher concentrations of chloride 
and bicarbonate were observed (up to 77.5 and $17.7 \mathrm{mEq}$. per L., respectively). Sodium was always the major cation although "common duct" potassium concentrations reached values as high as $10.6 \mathrm{mEq}$. per $\mathrm{L}$.

\section{Discrepancy between electrolyte concentration and osmolality}

In all bile samples there was an obvious discrepancy between the total electrolyte concentration (sum of anions plus cations) and the osmolality. This was most marked in specimens with high taurocholate concentration including those described in the preceding section (see Figure 1). The sum of the measured electrolyte concentrations reached values as high as $579 \mathrm{mMoles}$ per L., and would have been even higher if one had been able to convert from molar to molal concentrations and if other solutes had been included. This discrepancy has been noted by others $(13,15)$ and is almost certainly due to the tendency of the taurocholate ion to form large aggregates or micelles. According to Pethica and Schulman (16) micelle formation for pure sodium taurocholate begins at concentrations as low as $7.4 \times 10^{-3} \mathrm{M}$. This tendency is probably enhanced by the presence of lipids in the bile. The structure of these micelles is poorly understood but they are known to include an uncertain quantity of cation (17). Nevertheless the net effect of the aggregration phenomenon in bile is approximately the same as that which one would predict if all of the taurocholate ion were osmotically inactive and all of the other ions had an osmotic activity of 1.0 (15). Thus, over a wide range of biliary taurocholate concentrations the sum of the other major ions was consistent with the observed osmolality: $\left(\mathrm{Na}^{+}+\mathrm{K}^{+}+\right.$ $\left.\mathrm{Cl}^{-}+\mathrm{HCO}_{3}^{-}\right)=295 \pm$ S.D. $16 \mathrm{mEq}$. per L. There was an apparently linear correlation between taurocholate concentration $\left[\mathrm{T}^{-}\right]$and total cation. In 79 specimens of hepatic and "common duct bile," the coefficient of correlation was +0.97 and the following regression equation was obtained: $\left[\mathrm{T}^{-}\right]=2.03\left[\mathrm{Na}^{+}+\mathrm{K}^{+}\right]-302$.

\section{E. Bile flow in the absence of bile salt replacement}

In initial studies it was found that continuous bile collection over a period of two to five hours resulted in progressive and often profound de- pression in bile flow and taurocholate concentration. This experience was identical with that reported by Brooks, Buchholz and Gould (18) in the same type of preparation. Because of the resulting difficulty in obtaining adequate bile specimens and interpreting their composition, the technique of continuous intravenous taurocholate infusion was adopted.

\section{F. Control bile flow and composition during con- stant taurocholate infusion}

Sodium taurocholate was infused at a rate of $14.5 \mu$ Moles per minute throughout the course of at least five studies on each of the four dogs. Between 16 and 18 bile specimens were obtained in each dog, all at least one hour after onset of infusion. In all collection periods the taurocholate excretion rate was comparable to (or slightly greater than) the rate of administration. Mean excretion rates for the four dogs were 15.7, 15.7, 16.3 and $16.8 \mu$ Moles per minute and for the whole group $16.0 \pm$ S.D. $2.4 \mu$ Moles per minute. Thus the intravenous infusion of taurocholate proved to be a satisfactory way of establishing a state of constant and reproducible bile salt excretion rate during which other changes could be more readily interpreted.

There was no progressive diminution in bile flow. However, marked spontaneous variations in bile flow occurred frequently without obvious external stimuli. The range of bile flows encountered in each of the four dogs is shown in Table I (total range 0.074 to $0.347 \mathrm{ml}$. per minute).

Characteristic alterations in bile electrolyte composition accompanied these spontaneous changes in bile flow. There was a reciprocal relationship between flow and taurocholate concentration, indicating constancy of the excretion rate of this ion. As bile flow increased there was an increase in chloride concentration and a much more striking increase in bicarbonate concentration and $\mathrm{pH}$. This relationship is illustrated in Figure 2 for one of the dogs. In each animal the composition observed at a given rate of bile flow was consistent from one study to another. The concentrations of bicarbonate, chloride, and taurocholate and the $\mathrm{pH}$ in the specimens with the highest and lowest spontaneous flows are shown in Table I. In all 
TABLE I

Relationship between bile flow and electrolyte composition during intravenous sodium taurocholate infusion at $14.5 \mu$ Moles per minute

\begin{tabular}{|c|c|c|c|c|c|c|c|c|}
\hline Dog & Condition & Bile flow & $\mathrm{Na}^{+}$ & $\mathrm{K}^{+}$ & $\mathrm{HCO}_{3}^{-}$ & $\mathrm{Cl}^{-}$ & $\begin{array}{l}\text { Tauro- } \\
\text { cholate }\end{array}$ & $\mathrm{pH}$ \\
\hline $\begin{array}{l}\text { Norma } \\
20.9 \mathrm{Kg} .\end{array}$ & $\begin{array}{l}\text { Spontaneous flow } \\
\text { Secretin I.V.* } \\
\text { Intraduodenal HCl } \\
\text { Acetazolamide I.V. }\end{array}$ & $\begin{array}{l}\text { ml./min. } \\
0.074 \text { (min.) } \\
0.191 \text { (max.) } \\
0.315 \\
0.230 \\
0.174\end{array}$ & $\begin{array}{c}m E q . / L . \\
240.4 \\
200.8 \\
181.4 \\
182.0 \\
180.0\end{array}$ & $\begin{array}{c}m E q . / L . \\
7.6 \\
6.0 \\
5.6 \\
5.6 \\
5.7\end{array}$ & $\begin{array}{c}m E q . / L . \\
16.0 \\
45.7 \\
58.3 \\
58.0 \\
25.7\end{array}$ & $\begin{array}{c}m E q . / L \\
40.5 \\
55.4 \\
59.7 \\
67.7 \\
83.3\end{array}$ & $\begin{array}{c}m E q . / L \\
191.5 \\
105.7 \\
69.1 \\
62.0 \\
76.8\end{array}$ & $\begin{array}{l}7.03 \\
7.61 \\
7.76 \\
7.75 \\
7.11\end{array}$ \\
\hline $\begin{array}{l}\text { Cora } \\
24.0 \mathrm{Kg} \text {. }\end{array}$ & $\begin{array}{l}\text { Spontaneous flow } \\
\text { Secretin I.V.* } \\
\text { Intraduodenal HCl } \\
\text { Acetazolamide I.V. }\end{array}$ & $\begin{array}{l}0.110 \text { (min.) } \\
0.164(\max .) \\
0.311 \\
0.285 \\
0.355\end{array}$ & $\begin{array}{l}222.8 \\
179.0 \\
177.0 \\
176.0 \\
162.8\end{array}$ & $\begin{array}{l}8.0 \\
6.9 \\
5.6 \\
5.7 \\
4.9\end{array}$ & $\begin{array}{r}5.7 \\
33.0 \\
59.8 \\
59.2 \\
16.9\end{array}$ & $\begin{array}{l}53.1 \\
61.5 \\
75.4 \\
71.3 \\
98.0\end{array}$ & $\begin{array}{r}161.9 \\
91.4 \\
47.3 \\
51.1 \\
52.8\end{array}$ & $\begin{array}{l}6.71 \\
7.43 \\
7.78 \\
7.76 \\
7.04\end{array}$ \\
\hline $\begin{array}{l}\text { Dali } \\
22.7 \mathrm{Kg}\end{array}$ & $\begin{array}{l}\text { Spontaneous flow } \\
\text { Secretin I.V.* } \\
\text { Intraduodenal HCl } \\
\text { Acetazolamide I.V. }\end{array}$ & $\begin{array}{l}0.082 \text { (min.) } \\
0.347 \text { (max.) } \\
0.205 \\
0.300 \\
0.366\end{array}$ & $\begin{array}{l}242.4 \\
182.4 \\
182.4 \\
176.0 \\
173.6\end{array}$ & $\begin{array}{l}7.2 \\
7.0 \\
5.2 \\
5.5 \\
5.4\end{array}$ & $\begin{array}{l}10.1 \\
50.9 \\
48.0 \\
52.3 \\
37.3\end{array}$ & $\begin{array}{l}38.3 \\
76.0 \\
77.0 \\
69.9 \\
88.8\end{array}$ & $\begin{array}{r}201.0 \\
62.5 \\
62.7 \\
59.5 \\
52.9\end{array}$ & $\begin{array}{l}6.90 \\
7.81 \\
7.74 \\
7.75 \\
7.67\end{array}$ \\
\hline $\begin{array}{l}\text { Isolde } \\
30.2 \mathrm{Kg} \text {. }\end{array}$ & $\begin{array}{l}\text { Spontaneous flow } \\
\text { Secretin I.V.* } \\
\text { Intraduodenal HCl } \\
\text { Acetazolamide I.V. }\end{array}$ & $\begin{array}{l}0.140 \text { (min.) } \\
0.194 \text { (max.) } \\
0.415 \\
0.369 \\
0.340\end{array}$ & $\begin{array}{l}184.8 \\
176.0 \\
181.2 \\
181.0 \\
158.0\end{array}$ & $\begin{array}{l}6.3 \\
6.0 \\
5.9 \\
5.6 \\
5.5\end{array}$ & $\begin{array}{r}8.2 \\
27.5 \\
46.1 \\
42.3 \\
22.0\end{array}$ & $\begin{array}{r}82.8 \\
85.3 \\
102.3 \\
95.3 \\
94.9\end{array}$ & $\begin{array}{r}100.2 \\
69.2 \\
38.7 \\
49.0 \\
46.9\end{array}$ & $\begin{array}{l}6.92 \\
7.44 \\
7.74 \\
7.65 \\
7.29\end{array}$ \\
\hline
\end{tabular}

* The peak bile flows observed after secretin administration in the four dogs were $0.533,0.440,0.567$ and $0.475 \mathrm{ml}$. per minute, respectively. It was necessary to discard from 2 to $4 \mathrm{ml}$. of bile in order to avoid "dead space" errors. The values in the table represent the average flows observed during the collection of the actual specimens on which the analyses were performed.

dogs the composition of bile obtained at intermediate flows followed a pattern similar to that

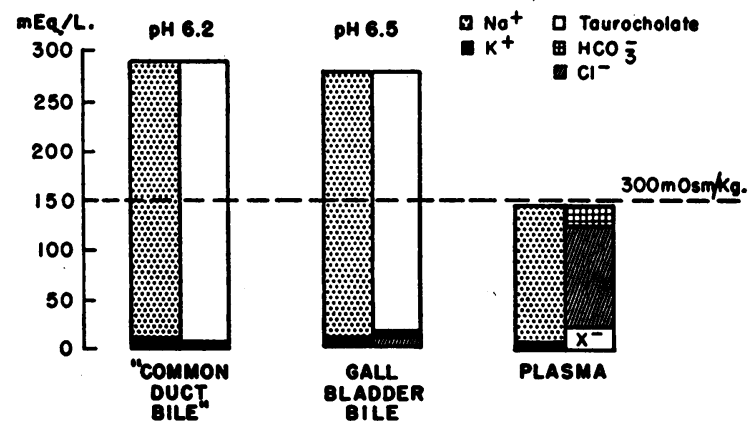

Fig. 1. Composition of "Common Duct Bile" Compared to the Composition of Canine Gall Bladder Bile and Plasma

Bile withdrawn from the common bile duct immediately after catheterization of a fasting cholecystectomized animal (left) had a high taurocholate concentration and very low $\mathrm{pH}$, chloride and bicarbonate. A typical specimen of canine gall bladder bile (center) had a similar composition. In contrast to plasma (right), the sum of the anion and cation concentrations in bile greatly exceeded the osmolality which was close to $300 \mathrm{mOsm}$. per $\mathrm{Kg}$. in all three solutions. illustrated in Figure 2. The total range of bicarbonate concentrations encountered was 5.7 to $50.9 \mathrm{mEq}$. per $\mathrm{L}$. and the $\mathrm{pH}$ range was 6.71 to 7.81 , the higher figures corresponding to a state of marked spontaneous choleresis. Sodium was always the major cation and the concentration of potassium never exceeded $8.0 \mathrm{mEq}$. per $\mathrm{L}$.

\section{G. Effect of intravenous secretin}

Within five minutes after the intravenous administration of 100 units of secretin a marked choleresis was observed in each dog, exceeding in magnitude the highest spontaneous bile flows observed at any time in the same animal. The duration of the effect was approximately 30 minutes, but the peak of the choleresis was so brief that it was sometimes impossible to obtain adequate specimens of bile representative of the highest flows achieved with this agent. Nevertheless, as shown in Table $I$ and Figure 2 very high values of bicarbonate (up to $59.8 \mathrm{mEq}$. per L.) and $\mathrm{pH}$ (up to 7.78) were seen in bile specimens obtained during secretin choleresis. A typical study in 
which secretin was administered is shown in Figure 3. Amylase was not detectable in undiluted bile samples obtained during secretin choleresis although samples of duodenal juice obtained at the same time gave a positive test in dilutions (both in water and bile) as high as 32 - to 512 -fold.

\section{H. Effect of intraduodenal hydrochloric acid}

In order to stimulate the production of endogenous secretin $0.05 \mathrm{~N}$ hydrochloric acid was infused into the duodenum (19). A sustained choleresis was observed which was accompanied by

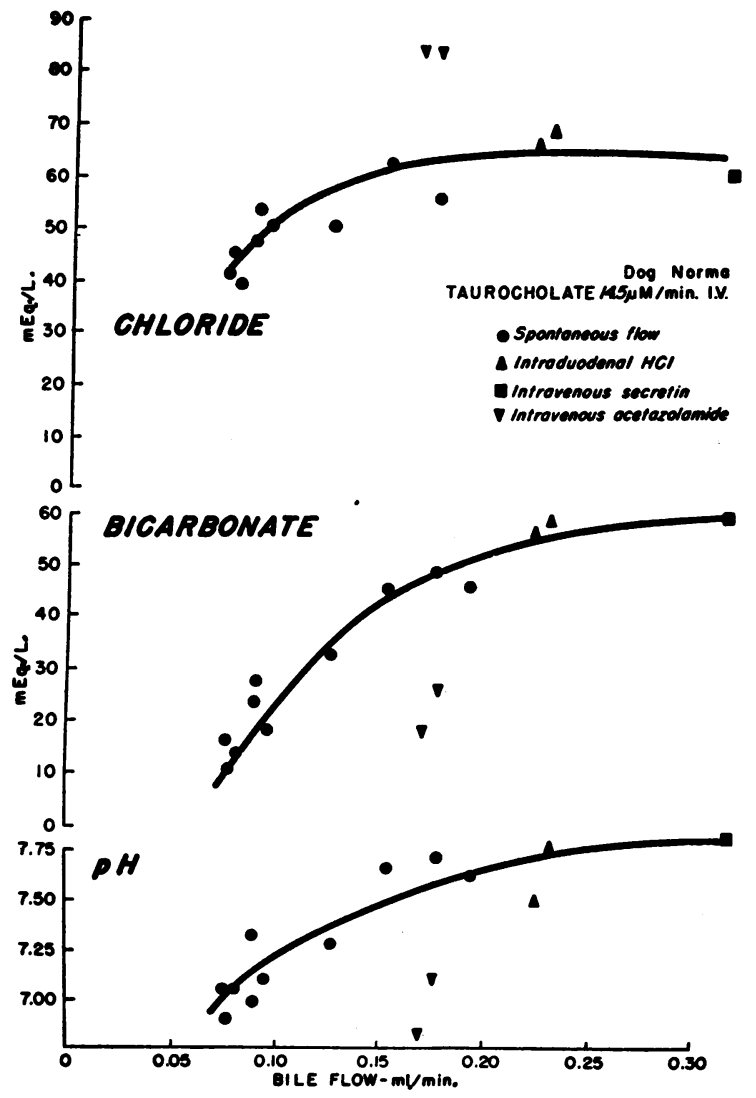

Fig. 2. Relationship Between Bile flow and CoMposition

Bile samples were all obtained at least one hour after starting intravenous sodium taurocholate infusion at $14.5 \mu$ Moles per minute. Spontaneous variations in flow were apparent and the highest flows were associated with the highest concentrations of bicarbonate and the highest $\mathrm{pH}$. Maximum flow, $\mathrm{pH}$ and bicarbonate concentration were observed after intravenous secretin or intraduodenal $\mathrm{HCl}$. After intravenous acetazolamide the chloride concentration was higher and the bicarbonate concentration lower than at comparable spontaneous flows.

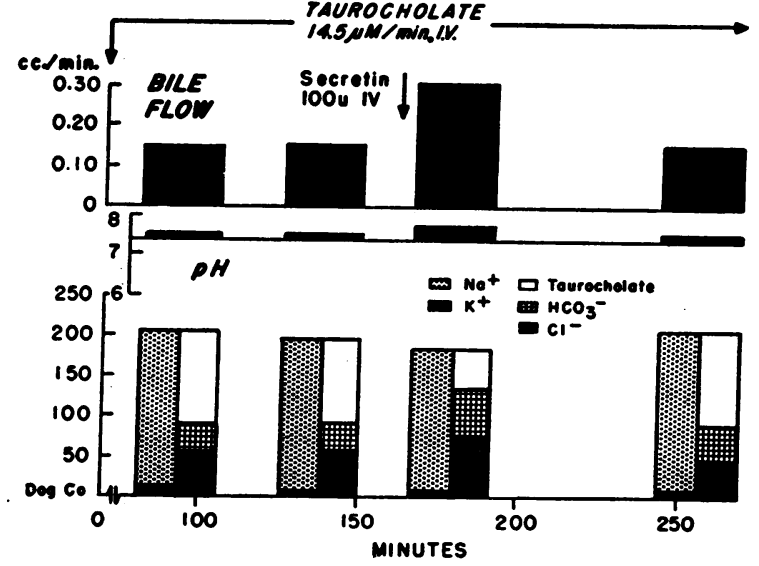

Fig. 3. Effect of Intravenous Secretin

During the course of continuous sodium taurocholate infusion the administration of secretin produced an increase in bile flow. Taurocholate concentration was correspondingly reduced, chloride concentration increased and there was a more marked increase in bicarbonate concentration and $\mathrm{pH}$.

changes in composition similar to those seen after exogenous secretin (Table I and Figure 2). Amylase was not detectable in this bile. Bile flow diminished rapidly within 20 minutes after stopping hydrochloric acid administration.

\section{Effect of acetazolamide}

The intravenous administration of acetazolamide sodium (Diamox ${ }^{\circledR}, 65 \mathrm{mg}$. per $\mathrm{Kg}$.) was followed in each case by a prompt choleresis. In all but one dog the bile flow after acetazolamide exceeded the highest spontaneous flows observed in the same animal. The excretion rate of taurocholate was unaffected. In every case the chloride concentration was higher and the bicarbonate concentration and $\mathrm{pH}$ were lower than those observed at similar bile flows under other circumstances (Table I and Figure 2). Thus, in the choleresis produced by this agent, increased excretion of chloride is the predominant feature. In all dogs the choleretic effect was still apparent by the time the study was concluded 60 to 90 minutes after acetazolamide injection.

\section{J. Effect of higher rates of taurocholate infusion}

In the foregoing studies sodium taurocholate was infused at a rate of $14.5 \mu$ Moles per minute. For comparison one study was conducted on each 
dog at an infusion rate of $38.4 \mu$ Moles per minute. The rate of taurocholate excretion was correspondingly increased (37.0 \pm S.D. $3.1 \mu$ Moles per minute). The results are shown in Table II. As anticipated, the higher rate of taurocholate excretion was accompanied by higher bile flows (range of flows, 0.214 to $0.460 \mathrm{ml}$. per minute). Although only two to three control specimens were obtained in each dog at this infusion rate, spontaneous variations in flow were again apparent. As in the preceding studies the highest flows were accompanied by the highest bicarbonate concentrations. Intravenous secretin (two dogs) and intraduodenal hydrochloric acid (two dogs) produced an increase in flow which appeared, if anything, to exceed the choleretic response produced by these agents at the lower rate of taurocholate infusion. Marked elevations in bicarbonate concentration and $\mathrm{pH}$ were again apparent during this choleresis (Table II).

\section{DISCUSSION}

These observations re-emphasize the marked dependence of bile production upon the rate of secretion of bile salts, and indicate the necessity for stabilization of this factor if other mechanisms are to be explored. When bile salt excretion rate is constant, a consistent relationship becomes apparent between bile flow and bile electrolyte composition.

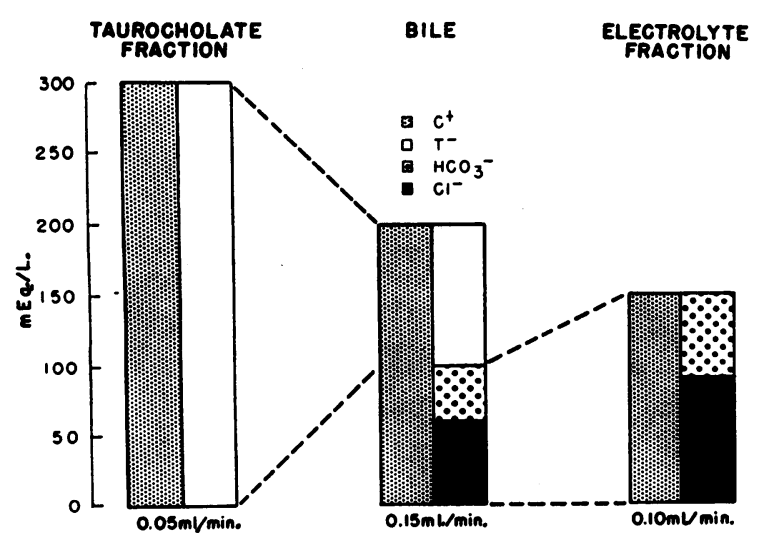

Fig. 4. Relationship Between the Hypothetical "Taurocholate Fraction" and "Electrolyte Fraction" in a Sample of Bille

The concentrations of solute in the two fractions are calculated on the assumption that each fraction is isosmotic, as indicated in the text.
The observed variations in flow and composition could be explained by the hypothesis that hepatic bile is formed by admixture of a number of solutions which differ from one another in composition and mode of production. With the limited evidence at hand, it appears reasonable for the sake of simplicity to regard each bile specimen as a mixture of two hypothetical isosmotic components (Figure 4). One of these components, a pure solution of taurocholate and its accompanying cations, has been designated the "taurocholate fraction." In view of the apparent osmotic inactivity of the taurocholate ion itself (see Part D of the preceding section) the total ionic concentration of this component (anion plus cation) should be roughly $600 \mathrm{mMoles}$ per L. if the solution is to be isosmotic with respect to plasma. A concentration of this magnitude was, in fact, approached in some specimens of "common duct bile" which were nearly pure taurocholate solutions (see Section C). The second component, designated the "electrolyte fraction," is a solution of chloride and bicarbonate and their accompanying cations. Consistent with the postulated isosmotic character of this solution, its total ionic concentration should be roughly 300 mMoles per L. (assuming an osmotic activity of 1.0 for these ions), and the sum $\left[\mathrm{Cl}^{-}\right]+\left[\mathrm{HCO}_{3}^{-}\right]$would be approximately $150 \mathrm{mEq}$. per $\mathrm{L}$. The presence of other constituents such as phosphate and sulfate has been disregarded since the concentrations of these anions in bile has been shown by other workers to be quite low (14).

At any given constant rate of taurocholate excretion the output of the "taurocholate fraction" would be constant, and variations in total bile flow and composition could be equated to changes in the output and composition of the "electrolyte fraction," which can be calculated as follows:

$$
\begin{aligned}
\mathrm{V}_{\mathrm{E}} & =\mathrm{V} \cdot \frac{\left[\mathrm{Cl}^{-}\right]+\left[\mathrm{HCO}_{3}^{-}\right]}{150} \\
{\left[\mathrm{Cl}^{-}\right]_{\mathrm{E}} } & =\frac{\mathrm{V}}{\mathrm{V}_{\mathrm{E}}} \cdot\left[\mathrm{Cl}^{-}\right] \\
{\left[\mathrm{HCO}_{3}^{-}\right]_{\mathrm{E}} } & =\frac{\mathrm{V}}{\mathrm{V}_{\mathrm{E}}} \cdot\left[\mathrm{HCO}_{3}^{-}\right]
\end{aligned}
$$

where: $\left[\mathrm{Cl}^{-}\right]$and $\left[\mathrm{HCO}_{3}{ }^{-}\right]=$chloride and bicarbonate concentrations in whole bile in milliequivalents per liter; $\left[\mathrm{Cl}^{-}\right]_{\mathrm{E}}$ and $\left[\mathrm{HCO}_{3}{ }^{-}\right]_{\mathrm{E}}=$ chloride and bicarbonate concentrations in 
TABLE II

Relationship between bile flow and electrolyte composition during intravenous sodium taurocholate infusion at $38.4 \mu$ Moles per minute

\begin{tabular}{|c|c|c|c|c|c|c|c|c|}
\hline Dog & Condition & Bile flow & $\mathrm{Na}^{+}$ & $\mathbf{K}^{+}$ & $\mathrm{HCO}_{3}^{-}$ & $\mathrm{Cl}^{-}$ & $\begin{array}{l}\text { Tauro- } \\
\text { cholate }\end{array}$ & $\mathrm{pH}$ \\
\hline Norma & $\begin{array}{l}\text { Spontaneous flow } \\
\text { Intraduodenal } \mathrm{HCl}\end{array}$ & $\begin{array}{l}\text { ml. } / \min . \\
0.221 \text { (min.) } \\
0.369 \text { (max.) } \\
0.550\end{array}$ & $\begin{array}{c}m E q . / L \\
217.8 \\
191.6 \\
182.0\end{array}$ & $\begin{array}{l}m E q . / L . \\
7.6 \\
6.85 \\
5.85\end{array}$ & $\begin{array}{c}m E q . / L \\
21.9 \\
46.4 \\
51.4\end{array}$ & $\begin{array}{c}m E q . / L . \\
49.1 \\
60.9 \\
72.5\end{array}$ & $\begin{array}{c}m E q . / L \\
154.4 \\
91.1 \\
64.0\end{array}$ & $\begin{array}{l}7.32 \\
7.59 \\
7.75\end{array}$ \\
\hline Cora & $\begin{array}{l}\text { Spontaneous flow } \\
\text { Secretin I.V. }\end{array}$ & $\begin{array}{l}0.300 \text { (min.) } \\
0.373 \text { (max.) } \\
0.572\end{array}$ & $\begin{array}{l}200 \\
197 \\
191.4\end{array}$ & $\begin{array}{l}7.5 \\
6.6 \\
6.6\end{array}$ & $\begin{array}{l}30.2 \\
40.2 \\
56.6\end{array}$ & $\begin{array}{l}56.0 \\
63.6 \\
80.6\end{array}$ & $\begin{array}{r}121.2 \\
99.8 \\
90.6\end{array}$ & $\begin{array}{l}7.46 \\
7.60 \\
7.76\end{array}$ \\
\hline Dali & $\begin{array}{l}\text { Spontaneous flow } \\
\text { Secretin I.V. }\end{array}$ & $\begin{array}{l}0.214 \text { (min.) } \\
0.300 \text { (max.) } \\
0.733\end{array}$ & $\begin{array}{l}230.4 \\
200.0 \\
202.8\end{array}$ & $\begin{array}{r}9.9 \\
11.9 \\
8.1\end{array}$ & $\begin{array}{l}12.2 \\
27.9 \\
43.8\end{array}$ & $\begin{array}{l}41.3 \\
57.2 \\
64.5\end{array}$ & $\begin{array}{l}186.8 \\
126.8 \\
102.6\end{array}$ & $\begin{array}{l}6.97 \\
7.49 \\
7.70\end{array}$ \\
\hline Isolde & $\begin{array}{l}\text { Spontaneous flow } \\
\text { Intraduodenal } \mathrm{HCl}\end{array}$ & $\begin{array}{l}0.347 \text { (min.) } \\
0.460 \text { (max.) } \\
0.560\end{array}$ & $\begin{array}{l}197.6 \\
201.2 \\
202.4\end{array}$ & $\begin{array}{l}6.2 \\
5.85 \\
6.0\end{array}$ & $\begin{array}{l}11.2 \\
20.1 \\
38.8\end{array}$ & $\begin{array}{l}77.6 \\
84.1 \\
94.7\end{array}$ & $\begin{array}{r}115.0 \\
92.9 \\
74.9\end{array}$ & $\begin{array}{l}7.13 \\
7.10 \\
7.68\end{array}$ \\
\hline
\end{tabular}

"electrolyte fraction" in milliequivalents per liter; $\mathrm{V}=$ bile flow in milliliters per minute; $\mathrm{V}_{\mathbf{E}}=$ output of "electrolyte fraction" in milliliters per minute.

When this calculation was applied to all bile specimens obtained during constant taurocholate infusion (14.5 $\mu$ Moles per minute), a relationship similar to that illustrated in Figure 5 became apparent in all of the animals. At lower rates of output chloride was the major anion in the hypothetical "electrolyte fraction." As the output of this fraction increased there was an increase in its bicarbonate concentration and a corresponding decrease in chloride concentration. At maximum choleresis (after secretin) the bicarbonate concentration achieved a value approximately equal to the chloride concentration ( $75 \mathrm{mEq}$. per L.). The relationship between chloride and bicarbonate after acetazolamide administration was entirely different (Figure 5). The effect of this agent could be equated to an increased output of "electrolyte fraction" in which chloride was the predominant anion.

The knowledge that bile production is dependent upon the rate of excretion of bile salts, and the observed relationship between flow and electrolyte composition at any constant rate of bile salt excretion are consistent with the view that at least the following processes are involved in normal bile formation.

1) The active secretion of a large quantity of relatively nondiffusible solute (bile salts) into the canalicular system would favor the addition, by passive diffusion, of a volume of water sufficient to maintain normal osmolality. Evidence for such a mechanism has been summarized in a recent re-

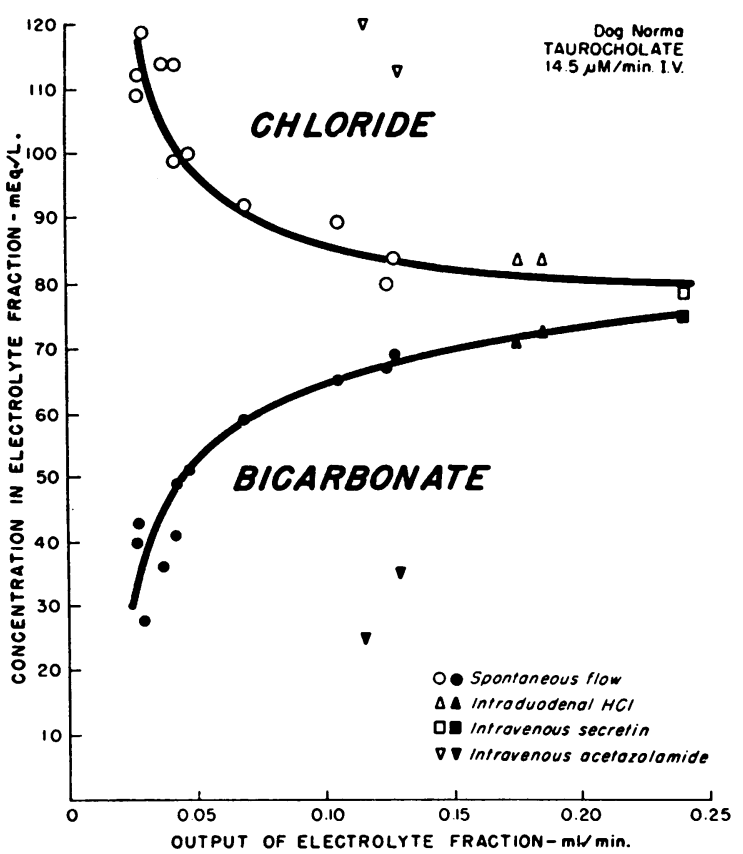

Fig. 5. Concentrations of Chloride and Bicarbonate Related to the OUtput of the Hypothetical "Electrolyte Fraction"

Bicarbonate concentration increases and chloride decreases during spontaneous or secretin-induced choleresis. After acetazolamide, there is a preponderance of chloride and correspondingly less bicarbonate. 
view by Sperber (20). It must be emphasized that the actual osmolality of canalicular bile is unknown and cannot necessarily be deduced from the observed osmolality of hepatic bile. Nevertheless, it does not seem necessary to invoke a specific mechanism for active water transport, and the likelihood of such a mechanism has been questioned on theoretical grounds (21). The passive diffusion of water in response to active bile salt secretion (and probably, in addition, in response to active secretion of other constituents in lesser amounts) would provide an adequate explanation for the choleretic effect of these substances, and would also be consistent with the observation that bile secretion can continue even when opposed by an appreciable hydrostatic pressure (22). In addition, as a part of this process, concentration gradients would be established which would favor the movement of other solutes into the bile by passive diffusion. Among the latter solutes would be that group of substances which Cook, Lawler, Calvin and Green have referred to as "unconcentrated" (23) and which Brauer has characterized as appearing in bile "in concentrations closely reflecting those of plasma" (24). An additional quantity of water would have to accompany these solutes for the maintenance of normal osmolality. At least part of the diffusible anion $\left(\mathrm{Cl}^{-}\right.$and $\mathrm{HCO}_{3}{ }^{-}$) could enter the bile by this type of passive diffusion owing to the Donnan effect.

2) The fact that secretin stimulates bile flow without increasing bile salt excretion has been well known for a number of years (6-8). The changes in the "electrolyte fraction" during variations in flow-whether spontaneous or induced by exogenous or endogenous secretin-suggest that the flow and composition of bile are modified by the addition of variable amounts of a solution which is similar in certain respects to pancreatic juice. Like pancreatic juice (25), this solution appears to contain an increasing concentration of bicarbonate as its output increases. Spontaneous changes in the output of this solution need not depend solely upon the elaboration of endogenous secretin. Like the output of pancreatic juice, bile flow has also been shown to vary in response to vagus and splanchnic nerve stimulation $(4,5)$ so that neurogenic factors may play an important role. The anatomical site of this mechanism has not been established. Although these observations were based on collections of bile through a catheter advanced well into the common bile duct, the possibility of accidental contamination with pancreatic juice was carefully considered. The absence of detectable concentrations of amylase in the bile appeared to rule this out. Moreover, high biliary concentrations of bicarbonate $(45.8,61.2$ and $40.5 \mathrm{mEq}$. per L.) have also been observed after secretin administration during three acute studies in which bile was collected through a catheter tied into the proximal end of the transected common bile duct.

In addition to the two mechanisms discussed above, it is also probable that reabsorption of various constituents may play a major role in determining the final flow and composition of bile. Reabsorption of electrolytes and water is a well established function of the gall bladder mucosa (26, 27). The similarity between the composition of "common duct bile" (see Section C) and gall bladder bile suggests that other parts of the biliary tract may possess similar reabsorptive mechanisms. Whether these are normally operative or whether they tend to "take over" only after cholecystectomy cannot be deduced from the present studies. Considering the high concentration of apparently nondiffusible anion in the bile, these mechanisms would necessarily involve active work against an appreciable oncotic gradient. At present, the actual evidence for reabsorption cannot be considered conclusive.

The choleresis induced by acetazolamide is difficult to correlate with the known pharmacologic activity of this agent. In view of the inhibitory effect of acetazolamide on the volume of pancreatic secretion (28) one would anticipate that this drug would, if anything, depress those processes in the biliary tract which normally elaborate a bicarbonate-rich fluid analogous to pancreatic juice. The fact that bicarbonate concentration during acetazolamide choleresis is lower than that observed during spontaneous or secretin-induced choleresis is therefore not surprising. However, the marked increase in flow and electrolyte excretion implies an altogether separate mechanism involving either augmentation of the movement of electrolytes into the biliary tract or inhibition of their reabsorption. The available data do not permit a choice between these alternatives nor is it easy to see how either could be attributed to carbonic 
anhydrase inhibition. The biliary concentration of acetazolamide itself has also not been determined since there are no satisfactory chemical methods available for this purpose. Previous workers have not observed any pharmacologic effect of acetazolamide on bile flow or composition in the rat (29) or man (30). However, in addition to species differences, the experimental circumstances in these instances were entirely different from those reported here.

It must be re-emphasized that bile production in the normal animal varies markedly in response to the demands of the organism. In the species in which it is present, the gall bladder participates in this process by storage, modification and intermittent release of the bile into the duodenum. Enterohepatic circulation of bile salts-the major normal stimulus for bile production-is therefore intermittent in character. Even in the absence of a gall bladder the common bile duct and its major radicles appear to subserve in a similar fashion. The "steady state" which one seeks to achieve by removal of the gall bladder, continuous emptying of the common bile duct and stabilization of the rate of bile salt secretion is therefore, in a sense, not "physiological." Nevertheless, it is possible, by means of this approach, to explore some of the specific mechanisms which are undoubtedly operative in normal bile production.

\section{SUM MARY}

The electrolyte composition of bile was studied in four unanesthetized cholecystectomized dogs. The biliary concentration of taurocholate was approximately equal over a wide range to the anioncation difference: $\left[\left(\mathrm{Na}^{+}+\mathrm{K}^{+}\right)-\left(\mathrm{Cl}^{-}+\mathrm{HCO}_{3}^{-}\right)\right]$. The osmolality of all bile samples (mean, 299 mOsm. per $\mathrm{Kg}$.) was indistinguishable from plasma osmolality (mean, 303) although the sum of the electrolyte concentrations in bile greatly exceeded 300 mMoles per L.- a discrepancy probably attributable to the aggregation of taurocholate ions.

Bile stored in the common bile duct of fasting dogs was similar to typical gall bladder bile (high concentration of taurocholate and low concentration of other anions) suggesting the possibility of reabsorptive mechanisms in the bile ducts.

Bile flow was dependent upon the availability of bile salt. When this factor was stabilized by constant infusions of sodium taurocholate, spontaneous variations in bile flow were observed in which high flows were accompanied by high bicarbonate concentration (maximum, $50.9 \mathrm{mEq}$. per L.) and $\mathrm{pH}$ (maximum, 7.81). Highest flows and bicarbonate concentrations were achieved with intravenous secretin or intraduodenal $\mathrm{HCl}$.

Intravenous acetazolamide produced a choleresis in which increased excretion of sodium chloride predominated.

The data suggest that bile production is dependent upon the active secretion of bile salts, and that the flow and composition of bile is further modified by the addition of a solution similar in electrolyte composition to pancreatic juice.

\section{ACKNOWLEDGMENTS}

The authors are indebted to Drs. Daniel Rudman and Irwin Mosbach for their helpful advice in connection with the estimation of bile acids, and to Mrs. Susan Stassa, Mrs. Ann Steele and Miss Evelyn Audioun for their valuable technical assistance.

\section{REFERENCES}

1. Schiff, M. Gallenbildung, abhängig von der Aufsaugung der Gallenstoffe. Pflüg. Arch. ges. Physiol. $1870,3,598$.

2. Jenke, M. Über den Stoffwechsel der Gallensaeuren. Naunyn-Schmiedeberg's Arch. exp. Path. Pharmak. 1932, 163, 175.

3. Schmidt, C. R., Beazell, J. M., Berman, A. L., Ivy, A. C., and Atkinson, A. J. Studies on the secretion of bile. Amer. J. Physiol. 1939, 126, 120.

4. Tanturi, C. A., and Ivy, A. C. On the existence of secretory nerves in the vagi for and the reflex excitation and inhibition of bile secretion. Amer. J. Physiol. 1938, 121, 270.

5. Tanturi, C. A., and Ivy, A. C. A study of the effect of vascular changes in the liver and the excitation of its nerve supply on the formation of bile. Amer. J. Physiol. 1938, 121, 61.

6. Bayliss, W. M., and Starling, E. H. The mechanism of pancreatic secretion. J. Physiol. (Lond.) $1902,28,325$.

7. Still, E. U., McBean, J. W., and Ries, F. A. Studies on the physiology of secretin. IV. The effect on the secretion of bile. Amer. J. Physiol. 1931, 99, 94.

8. Grossman, M. I., Janowitz, H. D., Ralston, H., and Kim, K. S. The effect of secretin on bile formation in man. Gastroenterology 1949, 12, 133.

9. Thomas, J. E. An improved cannula for gastric and intestinal fistulas. Proc. Soc. exp. Biol. (N. Y.) 1941, 46, 260. 
10. Van Slyke, D. D., and Neill, J. M. The determination of gases in blood and other solutions by vacuum extraction and manometric measurement. J. biol. Chem. 1924, 61, 523.

11. Cotlove, E., Trantham, H. V., and Bowman, R. L. An instrument and method for automatic, rapid, accurate, and sensitive titration of chloride in biologic samples. J. Lab. clin. Med. 1958, 51, 461.

12. Mosbach, E. H., Kalinsky, H. J., Halpern, E., and Kendall, F. E. Determination of deoxycholic and cholic acids in bile. Arch. Biochem. 1954, 51, 402.

13. Gilman, A., and Cowgill, G. R. Osmotic relations between blood and body fluids. IV. Pancreatic juice, bile and lymph. Amer. J. Physiol. 1933, $104,476$.

14. Sobotka, H. Physiological Chemistry of the Bile. Baltimore, The Williams and Wilkins Co., 1937, p. 51.

15. Ravdin, I. S., Johnston, C. G., Riegel, C., and Wright, S. L., Jr. Studies of gall-bladder function. VII. The anion-cation content of hepatic and gall-bladder bile. Amer. J. Physiol. 1932, 100, 317.

16. Pethica, B. A., and Schulman, J. H. Haemolytic and surface activity of sodium taurocholate. Nature (Lond.) 1952, 170, 117.

17. McBain, E. L., and Hutchinson, E. Solubilization and related phenomena. New York, Academic Press Inc., 1955, p. 147.

18. Brooks, F. P., Buchholz, R., and Gould, B. The flow and composition of bile in the unanesthetized dog (abstract). Amer. J. med. Sci. 1958, 235, 734.

19. Thomas, J. E., and Crider, J. O. A quantitative study of acid in the intestine as a stimulus for the pancreas. Amer. J. Physiol. 1940, 131, 349.

20. Sperber, I. Secretion of organic anions in the formation of urine and bile. Pharmacol. Rev. 1959, 11, 109.
21. Berliner, R. W., Levinsky, N. G., Davidson, D. G., and Eden, M. Dilution and concentration of the urine and the action of antidiuretic hormone. Amer. J. Med. 1958, 24, 730.

22. Brauer, R. W., Leong, G. F., and Holloway, R. J. Mechanics of bile secretion. Effect of perfusion pressure and temperature on bile flow and bile secretion pressure. Amer. J. Physiol. 1954, 177, 103.

23. Cook, D. L., Lawler, C. A., Calvin, L. D., and Green, D. M. Mechanisms of bile formation. Amer. J. Physiol. 1952, 171, 62.

24. Brauer, R. W. Mechanisms of bile secretion. J. Amer. med. Ass. 1959, 169, 1462.

25. Hart, W. M., and Thomas, J. E. Bicarbonate and chloride of pancreatic juice secreted in response to various stimuli. Gastroenterology 1945, 4, 409.

26. Rous, P., and McMaster, P. D. The concentrating activity of the gall blader. J. exp. Med. 1921, 34, 47.

27. Ravdin, I. S., Johnston, C. G., Austin, J. H., and Riegel, C. Studies of gall-bladder function. IV. The absorption of chloride from the bile-free gall bladder. Amer. J. Physiol. 1932, 99, 638.

28. Birnbaum, D., and Hollander, F. Inhibition of pancreatic secretion by the carbonic anhydrase inhibitor 2-acetyl-amino-1,3,4- thiadiazole-5-sulfonamide, Diamox (6063). Amer. J. Physiol. 1953, 174, 191.

29. Bizard, G., Vanlerenberghe, J., Guerrin, F., and Godchaux, R. Rôle de l'anhydrase carbonique dans la formation de la bile. J. Physiol. (Paris) 1958, 50, 155.

30. Fink, S. Studies on hepatic bile obtained from a patient with an external biliary fistula; its composition and changes after Diamox administration. New Engl. J. Med. 1956, 254, 258. 